\section{As Novas Ideias no Início dos Tempos Modernos}

\section{New Ideas in the Beginning of Modern Times}

\section{Resumo}

Este estudo tem por objetivo analisar alguns pontos da obra Novum Organum de Francis Bacon a luz da história da ciência. Três tópicos são inseridos para uma rápida análise das técnicas no final do século XVI e no início do século XVII como a investigação dos fenômenos naturais, os homens da ciência em torno de Bacon e as técnicas no pensamento baconiano. Como resultado, o estudo ilustrou as novas ideias que permeavam nos homens da ciência no início da modernidade.

Palavras-chave: História da Ciência, Francis Bacon, Novum Organum, Técnicas, Séculos XVI e XVII.

\section{Abstract}

This study aims to examine some of the work points Novum Organum of Francis Bacon the light of the history of science. Three topics are inserted for rapid analysis of the technical in the late sixteenth century and early seventeenth century as the investigation of natural phenomena, men of science around Bacon and techniques in Baconian thought. As a result, of the study illustrated the new ideas that permeated the men of science at the beginning of modernity.

Keywords: History of Science, Francis Bacon, Novum Organum, technical, sixteenth and seventeenth centuries.
Prof. Dr. Ricardo Dalla Costa

Dr. História da Ciência. Docente e Pesquisador da Universidade Estadual do Norte do Paraná (UENP) - Colegiado de Ciências Econômicas.

E-mail: dcricoo@gmail.com ; dallacosta@uenp.edu.br. 


\section{Introdução}

Inicia-se esse estudo com a obra Novum Organum' de Francis Bacon (1561-1626), escrito em 1620 ao estilo de aforismos como os "antigos investigadores da verdade, com mais fidelidade e sucesso" (BACON, 1999, p.68)², pela lógica exposta através da ciência que era orientada pela técnica. Deste modo, a perspectiva que Bacon difundia na observação e na experiência era um novo instrumento de investigação a analogia de um novo mundo bem como um continente inexplorado como ilustrado no frontispício do Novum Organum, um navio a vela (Figura 1) passando pelas Colunas de Hércules (o estreito de Gibraltar) significando o rompimento dos limites do conhecimento do velho mundo e trazendo consigo novas ideias e descobertas (VICKERS, 1992, p.495).

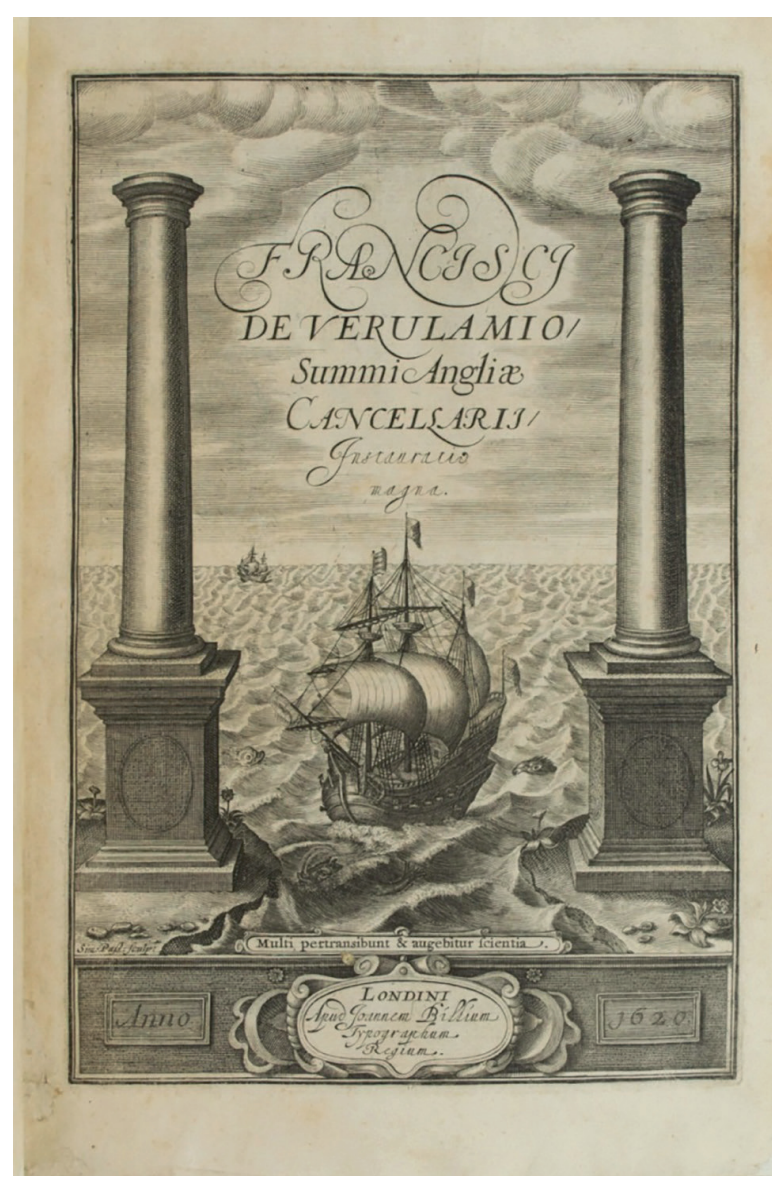

Figura 1 - Frontispício do Novum Organum, 1620
Bacon apostava na abertura do novo a ser descoberto, na investigação do desconhecido além dos confins do mediterrâneo. O pictograma associa a aquisição do novo conhecimento com viagens de navios para terras além da Europa (BASSALA, 1967, p.156) e o rompimento das colunas de Hércules fora a "mais importante das razões que alicerçam a esperança" (BACON, 1999, p.75)3. De tal modo,

\begin{abstract}
Cette caravelle qui franchit, toutes voiles gonflées, les deux colonnes symboliant les colonnes d'Hercules, et que l'on voit encore à l'horizon cinglant vers le large, rerpésente à mes yeux le dynamisme créateur, inventeur-découvreur, de cette époque de la civilization européenne (...) [Esta caravela que atravessa todas as velas enfunadas, colunas simbolizando as Colunas de Hércules, e ainda ver o horizonte em direção ao mar mordaz, representa para mim o dinamismo criativo, inventor, descobridor, desta vez civilização europeia] (MARGOLIN, 1985, p.11).
\end{abstract}

Embora no início da modernidade a ciência ainda fosse interpretada como um dogma de fét via crença religiosa como concepção de mundo e ao mesmo tempo a "science is not a dogma to be embraced but a calling to be pursued [ciência não era um dogma a ser abraçada, mas a ser perseguida]" (WHEELER, 1999, p.21), ia de encontro à resistência do forte viés aristotélico inexoravelmente praticado pela Igreja como "garantia indispensável das verdades da fé e não tolerava qualquer novo sistema que viesse por o antigo em dúvida" (BERNAL, 1969, p.442). A fé outrora mesclada com a religião conjuntamente com a ignorância e mesmo o misticismo descaracterizava a ciência e em refutação aos argumentos teólogos, Bacon frisou em "não misturar ou confundir imprudentemente esses saberes entre si" (BACON, 2007, p.25), isto é, o

3 NO, I, XCIV.

4 Veja a vulgata latina na Figura 1 evidencia os pilares da pesquisa (e com significado escatológico): "Multi pertransibunt et augebitur scientia [atravesse e aumente do conhecimento]". Passagem bíblica do Livro de Daniel (12:04).

1 Peça central da Instauratio Magna.
2 Novum Organum, Livro I, Aforismo LXXXVI. 
homem moderno deveria se orientar pelo porvir, pelo futuro melhor.

Destarte, o pensamento baconiano compreendia a necessidade de propor uma abordagem que permitisse a reforma do saber de forma a restaurar o domínio do homem sobre a natureza, ou mesmo, a informação experimental a ser instaurada nos procedimentos a propósito do ângulo da investigação científica "que são fundadas na natureza e se enriquecem das luzes da experiência" e "a esses experimentos costumamos designar por lucíferos, para diferenciá-los dos que chamamos de frutíferos" (BACON, 1999, p.59 e 78)

A releitura da obra Novum Organum ilustra o novo processo de investigação da natureza em diversas instâncias, como o calor, o fluxo e refluxo do mar, o movimento espontâneo de rotação, do peso e da gravidade, a substância corpórea que forma a lua, os corpos projetados ao ar, o movimento súbito e violento de expansão da pólvora, a fase transitória e de extinção da chama e os espíritos dos corpos tangíveis.

\section{A investigação dos fenômenos naturais}

Os empreendidos realizados por Francis Bacon na sua filosofia em defesa de um novo saber interessa porque enfatizou a difusão e o avanço do conhecimento no início da modernidade pela ciência útil e universal através de seu método, com reflexos na experiência, no homem como "ministro e intérprete da natureza" (BACON, 1999, p.33) ${ }^{6}$ e no intercâmbio de experiências para fomentar a nova ciência.

O que se pretende destacar é a curiosidade que capacita o homem da ciência a pensar e sentir a necessidade de interpretar a natureza que se tornou menos espiritualista e mais mecanicista, isto é, uma compreensão e explicação mecânica para o novo mundo natural. Longe de uma explanação sobre método "indutivo (da observação para o raciocínio) como era o

5 NO, I, LXXIV e I, XCIX.

$6 \mathrm{NO}, \mathrm{I}, \mathrm{I}$. de Bacon" (ALFONSO-GOLDFARB, 2004, p.50), mas uma explanação do conhecimento geral e prático baseado na experimentação.

Assim, no início da modernidade

a indústria havia avançado enormemente e tinha um volume de novos feitos a seu crédito (a metalurgia, a mineração, a indústria militar, a indústria de corantes) que supriam os estudiosos não apenas com material original mas também com novos meios de experimentações, permitindo a construção de novos instrumentos. Pode-se dizer que a ciência experimental sistemática se tornou possivel a partir dessa época (HESSEN, 1992, p.46).

Para Ellis, um dos editores de The works of Francis Bacon, advertiu que a

\begin{abstract}
absolute certainty, and a mechanical mode of procedure such that all men should be capable of employing it, are thus two great features of the Baconian method. His system can never be rightly understood if they are neglected [certeza absoluta e um modo mecânico de processo de tal modo que todos os homens deve ser capaz de empregá-la, são, portanto, duas grandes características do método baconiano. Seu sistema nunca pode ser corretamente entendido se forem negligenciados] (ELLIS, 1857, p. 65).
\end{abstract}

A visão de Bacon para o homem da ciência entre finais do século XVI e início do século XVII começava por um indivíduo humilde como virtude indispensável ao engrandecimento do empreendimento, da fiabilidade, da cooperação e da confluência entre ciência e técnica como forma prática de poder social resultando no verdadeiro conhecimento lucífero. Nessa oportunidade, Rossi ilustra que

esta consciência do valor social e mundano da técnica encontra-se estreitamente ligada a outro motivo que perpassa continuamente o pensamento europeu 
do século XVI e que manifesta nos escritos dos maiores e mais famosos expoentes do humanismo inglês: o da superioridade de uma ciência útil frente a uma ciência desinteressada, e de um conhecimento capaz de incidir sobre a prática, em contraposição a um conhecimento de caráter exclusivamente o teórico (ROSSI, 2006, p. 94).

O estudo das técnicas ilustra um indicativo de novos tempos na época de Bacon que merece ser estudado por meio de uma abordagem historiográfica, em contextualização específica, na agregação de fontes e documentos na sua elaboração. Os escritos baconianos envolvem um arcabouço sobre assuntos filosóficos, jurídicos, políticos e históricos de conteúdo extenso e diversificado, contudo, este estudo amplia as técnicas como interação de novas ideias aos homens da ciência no início dos tempos modernos a observação e investigação dos fenômenos naturais. Ideias essas com tom de originalidade na construção da ciência.

Para Needham $(1977,194-5)$ no final do século XVI e no início do século XVII caracterizou-se na Europa Ocidental, e em especial na Inglaterra londrina, a primazia do resto do Ocidente, o florescimento da ciência moderna nas proximidades das extensões do Renascimento sob as vestes das estruturas sociais, políticas e, principalmente das intelectuais, que oportunizou uma fase em contemplação ao conhecimento proposto por Bacon. Pode-se resumir que esse "período no capital mercantil estava se tornando a força econômica predominante e a manufatura começava a se desenvolver" (HESSEN, 1992, p.42-3).

As duas primeiras estruturas coincidem com o florescimento da atividade econômica devido à praticidade pensamento que alargou o melhoramento das técnicas. A terceira estrutura estava ligada a filosofia e que por sua vez inspirava à pesquisa de caráter técnico e social sob a égide da ciência (THOM, 1985, p.163). Segundo Wheeler $(1999,23)$, para Bacon a filosofia significava ciência com conhecimentos práticos. Neste interim houve a transformação do sistema feudal (em especial sobre a economia feudal) em bases técnicas veiculadas a "nova ciência progressiva e experimental que veio substituir a ciência estática e racional da Idade Média" (BERNAL, 1969, p.334).

A arte humana imitava a natureza via observação intensificando e interagindo com sua magnificência. A intervenção na natureza em diferentes sentidos e aspectos forçavam o intelecto a fazer analogias investigativas, imitativas e inventivas. A imaginação era o talento indispensável ao homem da ciência uma vez que fomentava novas ideias e consequentes novas descobertas além da melhor compreensão das coisas ocultas da natureza. Assim, ao homem cabe "engendrar e introduzir nova natureza ou novas naturezas em um corpo dado, tal é a obra e o fito do poder humano" (BACON, 1999, p.101)7.

Deste modo, a nova natureza do homem é forjar coisas análogas ou artificiais "da mesma maneira que na vida política o caráter de cada um, sua secreta disposição de ânimo e sentimentos melhor se patenteiam em ocasiões de perturbação que em outras, de tal modo os segredos da natureza melhor se revelam quando esta é submetida aos assaltos das artes que quando deixada no seu curso natural" (IDEM, p.77) ${ }^{8}$. Igualmente, os segredos (das coisas) são revelados quando se constrange a natureza com artifícios propostos ou a analogia da célebre frase, "é preciso torcer a cauda do leão" para que a investigação possa avançar.

Bacon observava que era possível avançar nas investigações ao endereçamento de novas invenções, de novas artes ou produtos por três meios: o primeiro quando se caminha sozinho (pela escuridão), o segundo com auxílio de outrem (com mero tateio), e o terceiro, pelo aperfeiçoamento de novas técnicas ou pelo novo método para uma lógica inventiva (o archote acesso) (IBIDEM, p.64) .

\footnotetext{
NO, II, I

$8 \mathrm{NO}, \mathrm{I}, \mathrm{XCVIII}$.

9 NO, I, LXXXII
} 


\section{Homens da ciência em torno de Bacon}

Na história da ciência, Francis Bacon é conceituado como o moderno na sistematização lógica do procedimento científico e é prestigiado na Royal Society por idealizar e consagrar à pesquisa.

A academia inglesa tornou-se oficialmente, em 1660, a primeira sociedade a favor da ciência, e neste feito, a Figura 2 ilustra o frontispício de Thomas Sprat em que no "centro da imagem, tem-se o busto de Charles II, patrono da Sociedade Real, e à direita, Francis Bacon, posto expressamente como idealizador e proponente" (MARICONDA, 2007, p.508).

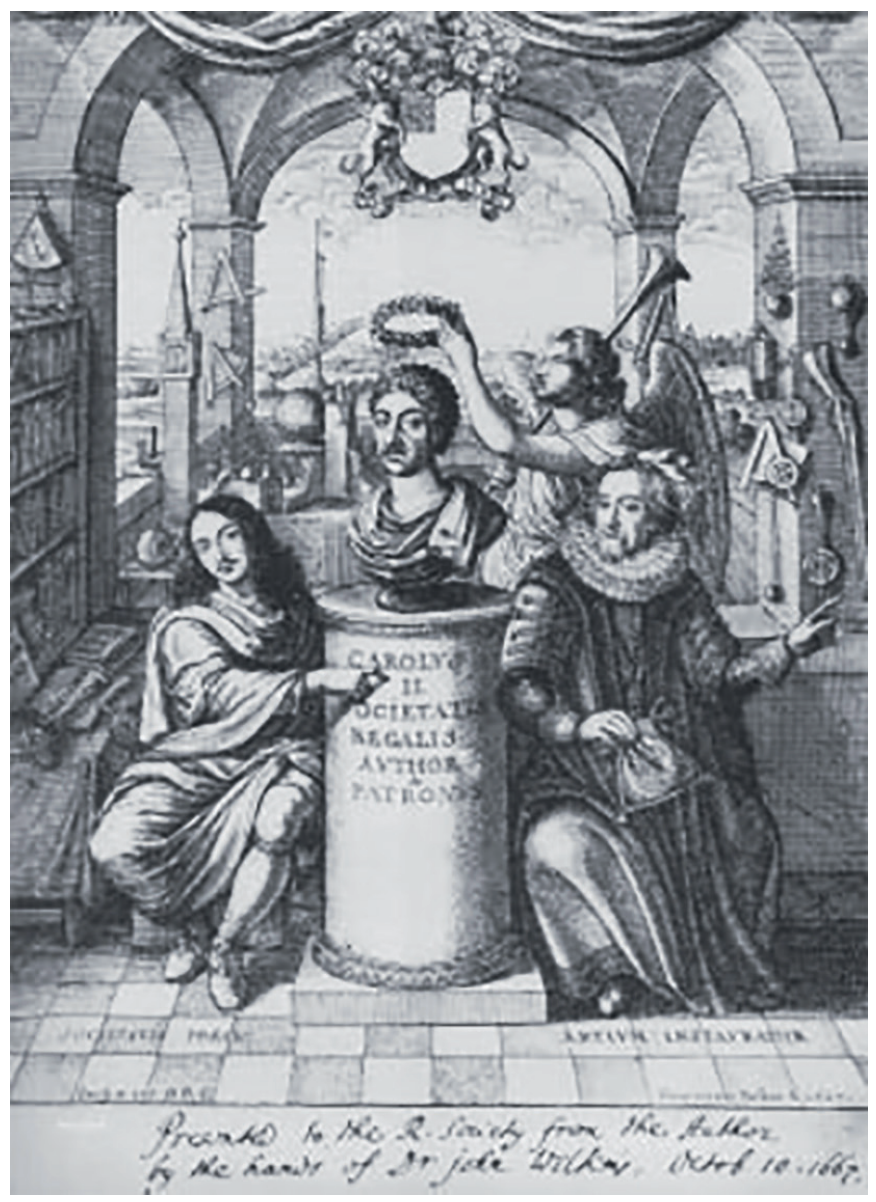

Figura 2 - Frontispício da History of the Royal Society, 1667

A cultura de Bacon avançava e selecionava ecleticamente leituras antigas e modernas que estavam no entorno da contemplação do seu novo método. O século XVII foi notável em vários aspectos, com destaque nos instrumentos e nas novas ideias registradas em importantes trabalhos.

Em se tratando do primeiro aspecto, destaca-se o microscópio no final do século XVI e o telescópio em 1608, pelo fabricante alemão de lentes Hans Lippershey (1570-1619), instrumento este que fora amplamente empregado pelo físico e matemático italiano Galileu Galilei (1564-1642) na defesa do copernicanismo ${ }^{10}$ e na visualização dos corpos celestes (BACON, 1999, p.171)". Outros inventos de grande valia foram o termômetro de Galileu, o barômetro do físico e matemático italiano Evangelista Torricelli (1608-1647) e a bomba de ar do físico alemão Otto von Guericke (1602-86).

No segundo aspecto, as ideias dos homens da ciência naquele ambiente em que Bacon anunciava suas diretrizes da pesquisa experimental destacavam-se: os trabalhos sobre magnetismo do médico e naturalista inglês William Gilbert (1540-1603), sobre a obra De Magnete, Magneticisque Corporibus, et de Magno Magnete Tellure (Sobre os ímãs, os corpos magnéticos e o grande imã terrestre), em 1600 , com ênfase na polaridade da agulha de ferro quando tocada pelo magneto (BACON, 1999, p.164) ${ }^{12}$; o fisiólogo e médico ${ }^{13}$ britânico William Harvey (1578-1657) que descobriu a circulação do sangue em 1628; a filosofia vitalista ao estilo neoplatônico do pensador italiano Bernardino Telesio (1509-1588) e do filósofo e humanista italiano Francesco Patrizi (15291597); nos experimentos do médico e teósofo inglês Robert Fludd (1574-1637); na história natural do padre jesuíta e historiador José de Acosta (1539-1600); na astronomia do dinamarquês Tycho Brahe (1546-1601); na filosofia do matemático francês René Descartes (15961650), em especial na geometria; na filosofia e na teoria do conhecimento do matemático inglês Thomas Hobbes (1588-1679); na filosofia do teólogo italiano Tommaso Campanela

\footnotetext{
10 A respeito à teoria planetária heliocêntrica.

$11 \mathrm{NO}, \mathrm{II}, \mathrm{XXXIV.}$

$12 \mathrm{NO}, \mathrm{II}, \mathrm{XXXVI}$.

13 Médico particular de Bacon.
} 
(1588-1679); no entusiasmo das concepções copernicanas na visão cósmica do filósofo italiano Giordano Bruno (1548-1600); nas teorias do polímata italiano Girolamo Cardano (1501-1576); nas leis da mecânica celeste do astrônomo e astrólogo alemão Johannes Kepler (1571-1630) e no enunciado da decodificação do logaritmo natural pelo matemático escocês John Napier (1550-1617) em 1614.

Outros homens cultos do início da modernidade que influenciaram as ideias de Bacon foram: os estudos dos corpos (BACON, 1999, p.166) ) $^{14}$ projetados ao ar do físico italiano Girolamo Fracastoro (1478-1553); o reformador educacional francês Petrus Ramus (1515-1572); o historiador político italiano Nicolau Maquiavel (1469-1527) e na admiração da filosofia de Bernardino Telesio (1509-1588).

No entorno desse ambiente Bacon fora crítico da doutrina escolástica devido à esterilidade da tradição filosófica uma vez que "queria libertar a humanidade dos velhos preconceitos tradicionais e criar um método para controlar as forças da natureza" (HESSEN, 1992, p.57) Também fora crítico da perpetuação aristotélica em que impunham interpretações teológicas.

As universidades, do século XV ao XVII, eram os centros científicos do feudalismo, não apenas portadoras das tradições feudais como também suas ativas defensoras (...) lutavam contra os novos e progressistas meios de produção, as universidades feudais combatiam a ciência nova. Aquilo que não se encontrava em Aristóteles, para elas simplesmente não existia (HESSEN, 1992, p.45).

\section{Portanto,}

Sem dúvida alguma, assim como muitas substâncias são por natureza sólidas, apodrecem e se corrompem em vermes, do mesmo modo o conhecimento bom e correto tem a propriedade de apodrecer e dissolver-se em incontáveis questões sutis ociosas, insanas e, por assim dizer, vermiculares, que têm de fato, uma certa animação e vivacidade, mas nenhuma correção nem bondade (BACON, 2007, p.49).

Por extensão, Bacon rejeitava considerar as artes mecânicas no plano acidental, ao acaso ou mesmo por mero tateio pela invenção, isto é, "la méthode ne précède pas l'invention [o método não precede a invenção]" (DELEULE, 1985, p.69). Em sua concepção sobre as artes mecânicas, reagia contra a tradição mágica mística, ocultista e supersticiosa que não compreendia a natureza com aumento de qualidade via atividades intelectuais. A mágica deveria ser aplicada a um aumento nas

indices de fécondité et d'utilité, pour lesquels il s'agit précisément de bâtir un cadre institutionnel destiné à favoriser l'essor collectif et systématique de la recherche (...) détacher les arts mécaniques de la 'ruse' alchimique [taxas de fertilidade e de utilidade, onde é precisamente para construir um quadro institucional de apoio ao desenvolvimento coletivo e sistemático de pesquisa] (IDEM, p.72).

Bacon ambicionava a restauração do saber ou no aumento da fertilidade na exploração em vários campos da pesquisa, e nesse sentido,

\footnotetext{
os alquimistas são, geralmente, representados como uma espécie de mágicos à procura da pedra filosofal. Na realidade, porém, a alquimia estava diretamente ligada à produção e o mistério que envolvia os alquimistas não deve ocultar a verdadeira natureza de suas pesquisas (HESSEN, 1992, p.49).
}

Contudo, endereçava argumentos especiais "a própria estirpe dos alquimistas [que] elabora uma filosofia fantástica e de pouco proveito, porque fundada em alguns poucos experimentos levados a cabo em suas oficinas" (BACON, 1999, p.46) ${ }^{15}$. Essa generalidade consiste apenas para

15 NO, I, LIV 
se comparar aos idola specus (ídolos da caverna). No primeiro livro do Progresso do Conhecimento (The Proficience and Advancement of Learning Divine and Humane), em 1605, Bacon refutava os ataques ao saber no universo dos seiscentos uma vez que defendia a ciência sobre égide da imaginação do homem dando crédito as técnicas. Como exemplo, "as ciências que em si têm tido melhor inteligência e de acordo com a imaginação do homem do que a razão são três: a astrologia, a magia natural e a alquimia, ciências cujos fins ou pretensões, não obstante, são nobres" (BACON, 2007, p.54). Em se tratando do primeiro, o homem se preocupa em descobrir a conexão entre o globo superior e o inferior; o segundo, levar a filosofia natural a uma variedade da especulação, e terceiro, separar partes dessemelhantes dos corpos e que se mistura na natureza.

Na formulação de uma estrutura de investigação sob os ares da nova ciência questionava-se a disciplina dos alquimistas renascentistas pela sistemática pouca investigativa e (re) produtiva nas suas experiências subjetivas e restritas a determinados fenômenos chegando a caracterização de uma balbúrdia. A fábula de Esopo (IDEM, p.55) em que ao morrer legou aos filhos ouro e que havia enterrado sob o vinhedo e que despertou a cobiça em certo afã em cavoucar todo o terreno. Não encontrando ouro algum, não compreenderam o verdadeiro sentido do aprimoramento de que ao revolver a terra foi possivel não só uma maior aeração no solo com benefício às raízes e as cepas, mas uma grande colheita no ano seguinte. A labuta na busca do ouro jorrou "luz grande [a um] número de bons e frutíferos inventos e experimentos" (IBIDEM).

A fábula abre espaço à ciência no que diz respeito ao aprimoramento das artes mecânicas ainda que sob os primeiros inventos (ainda que toscos), mas com melhoramentos pelas técnicas a exemplo que "a artilharia, a navegação, a imprensa e entre outras coisas semelhantes" (IBIDEM), com o tempo foram melhoradas, refinadas tornaram-se importante para o desenvolvimento de uma ciência mais operativa (técnica) e experimental.
Neste ínterim (aforismo LXIV), a censura fora também enérgica, como na relação da força elétrica dos corpos elaborada por Gilbert e pelas teorias de macrocosmos e microcosmos e as obcecadas experiências de destilações de Paracelso (1493-1541) (BACON, 1999, p.197) ${ }^{16}$. Sobre as experiências médicasalquímicas de Paracelso,

la critique porte ainsi sur l'application
singulière d'un défaut général de
l'entendement: la présomption, la
précipitation, la généralisation hâtive
de quelques résultats obtenus [a crítica
centra-se na aplicação particular de uma
falta geral de compreensão: a presunção,
a precipitação, a generalização apressada
de alguns resultados] (DELEULE, 1985, p.67).

Por outro lado, Bacon exaltava as descobertas de Gilbert sobre o magnetismo (BACON, 1999, p.155 e p.159) 1 .

A influência e o pensamento na ideologia baconiana caracterizava-se pelo reconhecimento dos procedimentos técnicos a luz do valor educativo e cultural no início dos tempos modernos (ROSSI, 2006, p.84) assim como "esta ciência, não apenas da natureza do intelecto, mas também das coisas" é o ponto de partida para compreensão da ciência no início da modernidade quando homens usavam livros para divulgar suas notas e experimentos sobre a natureza (e suas críticas), "pois tudo o que é digno de existir é digno de ciência, que é a imagem da realidade" (BACON, 1999, p.217 e p.90) ${ }^{18}$.

Alguns homens da ciência e filósofos das gerações do final do século XVI e início do século XVII que instauravam pensamentos modernos também compartilhavam do pensamento baconiano (ainda que não influenciados ou adeptos, mas no sentido de aproximação e rigidez na observação na experimentação) como fez Galileu Galilei, assim como outros pensadores a exemplo do filósofo e matemático inglês Thomas Robbes (1588-1679),

16 NO, II, XLVIII.

17 NO, II, XXXV e XXXVI.

$18 \mathrm{NO}$, II, LII e I, CXX. 
do químico e físico irlandês Robert Boyle (16271691), do filósofo inglês John Wilkins (1614-1672), do filósofo italiano Giambattista Vico (1668- 1744), do filósofo britânico William Pety (1623-1687), do filósofo inglês John Locke (1632-1704), do físico e matemático inglês Isaac Newton (1642-1717), do filósofo e historiador escocês David Hume (17111726) e do economista e filósofo francês Denis Diderot (1713-1784). A esse respeito, cita-se o exemplo do projeto de metafísica, gramática e lógica de John Wilkins intitulada de Essay towards a Real Character, and Philosophical Langange (1668) inspirado (JARDINE, 1985, p.148) no Novum Organum.

O método baconiano influenciou gerações europeias a exemplo do filósofo e matemático francês Pierre Gassendi (1592-1655), do matemático, teólogo e filósofo francês Marin Mersenne (1588-1648), do cientista inglês Robert Hooke (1635-1703) e do filósofo alemão Hermann Conring (1606-1681):

Il est clair, pour, Gassendi, Mersenne et Conring comme pour Hooke, que Bacon consacre plus la plus grande partie de son énergie intellectuelle dans de le Novum Organum (...) [Está claro, pois, Gassendi, Mersenne e Conring como Hooke, Bacon passa em grande parte da sua energia intelectual do Novum Organum] (IDEM, p.155).

Neste interim, Rossi ratifica a posição (ainda que difusa) de uma provável interação entre conhecimento técnico e ciência como "o trabalho técnico não pode, portanto, de maneira alguma andar disjunto do trabalho dos cientistas" (ROSSI, p.91 apud AGRICOLA, De la generatione de le cose che sotto la terra sono, Venetia, 1550, p.22). Deste modo, o filósofo e médico Georgius Agricola (1494-1555) cita o trabalho exercido na arte dos metaleiros, no campo, na arquitetura e na medicina praticado por presos que de uma forma ou de outra asseveravam o aprimoramento das técnicas (os artifícios e as potencialidades oportunizadas pela natureza). Bacon convalida que, "em primeiro lugar, parece-nos que a introdução de notáveis descobertas ocupa de longe o mais alto posto entre as ações humanas" (BACON, 1999, p.96) ${ }^{19}$. Assim, o livro de Agricola (De re metallica) valoriza o conhecimento técnico na melhor caracterização e descrição da natureza na sua compreensão.

\section{As técnicas no pensamento baconiano}

A Sabedoria dos Antigos (De Sapientia Veterum) destaca-se por ser uma obra notável, senão, um tesouro recuperado da antiguidade que evidencia fábulas gregas elegantes $^{20}$ sob um significado digno de preservação do conhecimento. A popularidade desta obra influenciou várias gerações (esquecidas) no início da modernidade.

A experientia literata ou experiência metódica e consciente ou aquela que procede por meio de técnicas fora compreendido por Bacon "comme une sorte de sagacité, de flair, volontiers appelée chase de Pan [como uma espécie de sabedoria, dom, voluntariamente a perseguir o chamado de Pan]" (DELEULE, 1985, p.74). Nesse sentido a fábula 'Pã, ou Natureza' compreende o chamado ao conhecimento, a experiência e a sagacidade em descobrir segredos, ou dito de outra forma,

\begin{abstract}
Pã, como a palavra o diz, representa e anuncia a Universalidade das Coisas, ou Natureza (...). Nada explica melhor a função de Pã que o epíteto de deus dos cacadores: toda ação natural, todo movimento e todo processo da natureza nada mais são que uma caçada. As ciências e as artes caçam suas obras (...) (BACON 2002, p.33 e p.36)
\end{abstract}

Bacon aproxima-se da capacidade inventiva da mente humana, isto é, uma mente restaurada capaz de alcançar à unidade da natureza descartando a invenção do plano acidental ou do mero acaso.

$19 \mathrm{NO}, \mathrm{I}, \mathrm{CXXIX}$

20 Um rápido elogio de Spedding em The letters and life of Francis Bacon, v.IV, p.142. 
A fábula 'Prometeu, ou condição humana' mostra a importância das técnicas como indicativo de novos tempos na época de Bacon marcou a evolução das ideias por meio da disseminação do conhecimento humano a semelhança "das corridas com tochas acesas, instituindo honra de Prometeu" (BACON, 2002, p.85), registro das grandes transformações na ciência. Naquela "atmosfera, havia a consciência de que os homens podem dispor - servindo-se da técnica e da colaboração - de um poder desmedido e que o palco dos empreendimentos humanos já não era mais uma cidade, mas o mundo" (ROSSI, 2006, p.143).

O pensamento baconiano ambicionava a ampliação e a preparação do espírito humano via "transmissão e na difusão do pensamento no seio de uma sociedade ainda aristocrática em seu contexto" (FEBVRE e MARTINS, 1992, p.18) porque o conhecimento proposto por Bacon contemplava a analogia de Prometeu "como o fogo em cuja memória e celebração foram criados tais jogos [corrida das tochas], alude às artes e ciências com prudência que a perfeição do conhecimento não cabe à rapidez ou a habilidade de um só investigador, mas de muitos" (BACON, 2002, p.85).

Neste particular o mito se destaca pelo fogo (as técnicas) como presente de Prometeu a humanidade. Bacon chama a atenção no que diz respeito do conhecimento de que se "não é possível cumprir-se bem uma corrida quando não foi estabelecida e prefixada a meta a ser atingida", assim como na melhora na vida na terra "a verdadeira e legítima meta das ciências é a de dotar a vida humana de novos inventos e recursos" (BACON, 1999, p.63)" ${ }^{21}$. As técnicas seriam "a verdadeira ordem da experiência, ao contrário, começa por, primeiro, acender o archote e, depois, com o archote mostrar o caminho, começando por uma experiência ordenada e medida" (IDEM, p.64) 22 .

21 NO, I, LXXXI.

$22 \mathrm{NO}, \mathrm{I}, \mathrm{LXXXII}$.
Merchant (2008) mostra esta analogia no frontispício do Novum Organum onde escreve que

\begin{abstract}
the image invokes Hercules's voyage to free Prometheus and, with him, liberate mankind to pursue knowledge of the arts and sciences [a imagem invoca viagem de Hércules para libertar Prometeu, e com ele, libertar a humanidade para buscar o conhecimento das artes e das ciências] (IDEM, 2008, p.747), [isto é, o] império do homem sobre as coisas se apoia unicamente nas artes e nas ciências (BACON, 1999, p.97) $)^{23}$.
\end{abstract}

A fábula 'Dédalo, ou o mecânico' evidencia os inventos mecânicos a extensão das técnicas e a visão do homem da ciência na compreensão da natureza e em interpretá-la. Primeiramente estava ligada a um dogma de fé sobre os mais diversos conceitos debatidos na Inglaterra seiscentista, e posteriormente, a instrumento de criação/prazer e destruição/morte.

Na pessoa de Dédalo, (...) os antigos viram
a industriosidade e a habilidade mecâni-
ca, juntamente com seus artifícios deso-
nestos e suas aplicações pervertidas. (...)
Entretanto, ganhou fama máxima por in-
venções ilícitas. (...) Decerto a vida huma-
na muito lhes deve, pois daí se tiram inú-
meras coisas úteis ao aparato religioso,
ao ornamento do Estado e ao universo da
cultura. No entanto, da mesma fonte pro-
manam os instrumentos da luxúria e até
da morte. (...) os venenos mais insidiosos,
as armas de guerra e outros engenhos
letais são frutos da invenção mecânica
(BACON, 2002, p.62-4).

O conhecimento era absorvido pelo intelecto se este estivesse livre de deturpações, fraquezas ou com forte tendência de expelir os ídolos (da tribo, da caverna, do fórum e do teatro) (BACON, 1999, p.40 ${ }^{24}$ para desbloquear a mente humana rumo aos horizontes das artes da investigação.

23 NO, I, CXXIX.

24 NO, I, XXXIX. 
Esse tom de tecnicismo direcionado ao prazer da criação de coisas constituía em novas ideias no início da modernidade, contudo, o homem devido à maldade distorce, degrada e leva a invenção para o lado obscuro que é a destruição e morte. É o caso da criação do Minotauro (o monstro), o labirinto (a natureza mecânica) e o novelo (engenho da experiência).

A Epistola ad Fulgentium (SPEDDING, ELLIS e HEATH, 1874, p.531-2) foi uma carta escrita por Bacon (Visconde de São Alban) entre 1624-26 que fez referência ao homem mecânico (machina intellectus) e as descobertas (inventa) lucíferas e precisas (exacta) que iriam conter os axiomas da experiência (BACON, 1999, p. 78) ${ }^{25}$. A ideia de homem inventor trás a lembrança do mito de Dédalos (BACON, 2002) que evidencia os artefatos ou inventos mecânicos com a mente humana a extensão das técnicas. Assim ilustra-se a passagem como uma "variedade e [d]o magnífico aparato de coisas introduzidas e acumuladas pelas artes mecânicas" (BACON, 1999, p.66)26.

Todos os feitos se cumprem com instrumentos e recursos auxiliares, de que dependem, em igual medida, tanto 0 intelecto quanto as mãos. Assim como os instrumentos mecânicos regulam e ampliam o movimento das mãos, os da mente aguçam o intelecto e o precavêm (BACON, 1999, p.33) ${ }^{27}$

Bacon refere ao intelecto por vezes limitado e por vezes enaltecido por "any apparel of words that can be put upon it [qualquer aparelho de palavras que pode ser colocado em cima dele]" (SPEDDING, ELLIS e HEATH, 1861, p.125), mas as palavras relacionam ao conhecimento que é comparado "the work of the Inventor, though a thing of less pomp and shew, is felt everywhere and lasts for ever [ao trabalho do Inventor, embora uma coisa de menos pompa e anunciado seja sentido em todos os lugares e dura para sempre]" (SPEDDING, ELLIS e HEATH, 1868, p.84).

$25 \mathrm{NO}, \mathrm{I}, \mathrm{XCIX}$

26 NO, I, LXXXV.

$27 \mathrm{NO}, \mathrm{I}, \mathrm{II}$.
A discussão caminhava para a cultura e a intersubjetividade entre métodos e artes mecânicas como capazes de revelar os processos efetivos da natureza, contexto esse ligado a investigação com fins de alargamento da capacidade de inventar. Assim, "au sens le plus large, car artes comprend aussi bien les sciences et les techniques dans leur diversité [no sentido mais amplo, como artes inclui tanto a ciência e a técnicas em sua diversidade]" (MARGOLIN, 1985, p.21), frisa-se que de fato, "as artes mecânicas, ao contrário, parecem a Bacon um novo e grande fato cultural e, em função da avaliação de seu significado e de sua importância para a vida da comunidade e para a pesquisa científica" (ROSSI, 2006, p.127).

Assim, a ideia dos procedimentos técnicos expostos pressupõe que a ciência posiciona-se como intermediária entre as artes mecânicas e não liberais na investigação da natureza no final do século XVI e início do século XVII. Isso contempla, a princípio, uma pretensão de convergência entre conhecimento técnico e a ciência.

Tal concepção levou Bacon ressaltar os três inventos ${ }^{28}$ mecânicos ${ }^{29}$ ou as "três descobertas [que] mudaram o aspecto e o estado das coisas em todo o mundo: a primeira nas letras, a segunda na arte militar e a terceira na navegação" (BACON, 1999, p.97) ${ }^{30}$. A importância dessas inovações técnicas trás o exemplo da impressão que refletia as inovações mecânicas (devido aos caracteres de metal móveis, da tinta a base de óleo e da prensa de madeira) amplamente empregadas na Europa a partir do século XVI. A imprensa foi no início da modernidade "um instrumento poderoso para difusão do conhecimento" (HESSEN, 1992, p.46); a pólvora que instigou várias nações para fins militare ${ }^{31}$ com grandes resultados alquímicos devido a sua composição de carvão vegetal, de salitre (nitrato de potássio) e sulfureto (base

28 Outras invenções como a seda, o açúcar e o papel também foram considerados, veja no NO, I, CX, p.84.

29 Invenções introduzidas no Ocidente durante no final do período medieval.

$30 \mathrm{NO}, \mathrm{I}, \mathrm{CXXIX}$.

31 O exemplo das armas de fogo veja no NO, II, XXXI, p.150. 
de enxofre) (BERNAL, 1969, p.348-9); a bússola "para investigação [d] a natureza de polaridade que tem a agulha de ferro quando tocada pelo magneto" (BACON, 1999, p.159) ${ }^{32}$ que envolveu a questão do magnetismo que deslumbraria pesquisas de Norman e Gilbert (BERNAL, 1969, p.345).

O manuscrito Praise of knowledge (MSS 6797, fo. 47), escrito por Bacon entre 1590-92, foi um projeto verdadeiro de ofício a ciência e a técnica. Exemplifica-se a importância dos três inventos:

Printing, a gross invention; artillery, a thing that lay not far out the way; the needle, a thing partly known before, what a change have these three made in the world in these times; the one in state of learning, the other in state of the war, the third in the state of treasure, commodities, and navigation [Impressão, uma invenção grosseira; artilharia, uma coisa que não estava longe do caminho; a agulha, uma coisa parcialmente conhecida antes, uma mudança que estes três fizeram no mundo nestes tempos; aquele em estado de aprendizagem, o outro em estado de guerra, a terceira no estado do tesouro, mercadorias e navegação] (SPEDDING, ELLIS e HEATH, 1861, p.125).

Na concepção baconiana, às artes mecânicas evidencia a "verdadeira e legítima meta das ciências [que] é a de dotar a vida humana de novos inventos e recursos" (BACON, 1999, p.64) ${ }^{33}$, e no contexto ilustrado, as três técnicas não só envolviam a manifestação do gênero humano, mas a compreensão da natureza, "pois a natureza não se vence se não quando se the obedece" (IDEM, p.33) ${ }^{34}$.

Neste particular, destacam-se duas atividades técnicas (navegação e a mineração) de grande valia porque envolviam os homens da ciência nos saberes e interesses da investigação com uso de instrumentos, engenhos e máquinas. A primeira envolvia uma complexa rede de agentes, de especialidades, de investimentos,

$32 \mathrm{NO}, \mathrm{II}, \mathrm{XXXVI.}$

$33 \mathrm{NO}, \mathrm{I}, \mathrm{LXXXI}$.

$34 \mathrm{NO}, \mathrm{I}$, III. levando a uma associação entre banqueiros, construtores de barcos, comerciantes e até os interesses do reino, pois envolvia inovações diversas (instrumentos), a exemplo da bússola, que era guia a novas descobertas, que contemplavam a cartografia, a defesa militar, as técnicas da navegação, assim como a astronomia, a geografia e a mecânica. É nesse sentido que Bacon presume "que a arte da invenção robustecer-se-á com as próprias descobertas" (BACON, 1999, p. 98) ${ }^{35}$. A segunda envolvia a busca de metais e minerais preciosos com fins industriais, comerciais e militares; adentrou na química, no magnetismo, na eletricidade e na metalurgia. $O$ registro dessas atividades fecha o ciclo, como Bacon ressaltou: "Eis por que por tantos séculos não se pôde contar com essa admirável invenção, tão propícia à propagação do saber" (IDEM, p. 84) ${ }^{36}$.

\section{Considerações Finais}

No final do século XVI a Europa Ocidental passava por uma crise econômica generalizada, contudo, o florescimento da ciência moderna no final da Idade Média e nas extensões do Renascimento acabou por refletir as vestes das novas estruturas sociais, políticas e principalmente, intelectuais, oportunizando uma fase de contemplação ao conhecimento.

A estrutura feudal deixou um legado econômico, técnico e político que norteou o início da modernidade na Europa Ocidental. A colheita dos frutos daquela época continha um discurso tendencioso entre o conhecimento técnico e a ciência, pois "não se pode estudar a ciência independentemente da técnica" (BERNAL, 1969, p.5).

O estudo das técnicas no início da modernidade ilustrou um indicativo de novos tempos nos empreendimentos realizados por Francis Bacon na sua filosofia em defesa de um novo saber. Os escritos baconianos envolveram um arcabouço sobre assuntos jurídicos, políticos e históricos de conteúdo extenso e diversificado, contudo,

35 NO, I, CXXX

$36 \mathrm{NO}, \mathrm{I}, \mathrm{CX}$. 
- objetivo deste estudo restringiu as técnicas como interação de novas ideias aos homens da ciência no início dos tempos modernos a observação e investigação dos fenômenos naturais.

A análise das técnicas ao longo dos seiscentos permitiu vislumbrar aquele ambiente de investigação dos fenômenos naturais revivificado pelos homens da ciência. O resultado esperado foi o avanço das novas ideias que desabrocharam de vez a ciência.

\section{Referências}

ALFONSO-GOLDFARB, A. M. O que é História da Ciência. $4^{a}$ reimpr. São Paulo: Brasiliense, 2004. BACON, F. Novum Organum ou verdadeiras indicações acerca da interpretação da natureza. 1620. Coleção Os Pensadores. Trad. J. R. de Andrade. São Paulo: Nova Cultural, 1999.

A Sabedoria dos Antigos (1609). Trad. G. C. C. de Souza. São Paulo: Editora Unesp, 2002.

. O Progresso do Conhecimento (1605).

Trad. R. Fiker. São Paulo: Editora Unesp, 2007.

BASALLA, G. The Spread of Western Science. Science 156 (maio 1967): 611-22.

BERNAL, J. D. A Ciência na História. Vol. II. Trad. A. N. Pedro. Lisboa: Livros Horizonte, 1969.

DELEULE, D. L'éthique baconianne et l'esprit de la science modern. In: MALHERBE, M.; POUSSEUR, J.-M. (Orgs.). Francis Bacon Science et Méthode, p.53-77. Nantes: Vrin, 1985.

ELLIS, R. L. General Preface. In: SPEDDING, J.; ELLIS, R. L.; HEATH, D. D, (Orgs.). The works of Francis Bacon, vol. I, p.61-127. Boston: Houghton e Mifflin, 1857. Reimp. fac-similar, EUA: Internet Archive, 2007.

FEBVRE, L.; MARTINS, H.-J. O aparecimento do livro. Trad. F. M. L. Moretto e G. M. Machado. São Paulo: Unesp; Hucitec, 1992.

HESSEN, B. As raízes socioeconômicas dos Principia de Newton. In: GAMA, R. (Org.). Ciência e Técnica (antologia de textos históricos). São Paulo: T. A. Queirós, 1992.
JARDINE, L. Experientia Literata ou Novum Organum? Le dilemme de la méthode scientifique de Bacon. In: MALHERBE, M.; POUSSEUR, J.-M. (Org.). Francis Bacon Science et Méthode, p.135-157. Nantes: Vrin, 1985.

MARGOLIN, J.-C. L'idée de nouveaute et ses points d'application dans le Novum Organum de Bacon. In: MALHERBE, M.; POUSSEUR, J.-M. (Org.). Francis Bacon Science et Méthode, p.1136. Nantes: Vrin, 1985.

MARICONDA, P. R. Francis Bacon e as marés: a concepção da natureza e o Mecanicismo. Scientiae Studia, 5, 4, p.501-19, 2007. Disponível em: <http:// dx.doi.org/10.1590/S1678-31662007000400004>. Acesso em: 1 de setembro de 2014.

MERCHANT, C. The violence of impediments: Francis Bacon and the origins of Experimentation. Isis, 99, 4, p.737-760, 2008. Disponível em: <http:// www.jstor.org/stable/10.1086/597767>. Acesso em: 17 de março de 2014.

NEEDHAM, J. La Gran Titutación: ciencia y sociedade em Oriente y Occidente. Trad. R. M. Silvestre e M. T. de la T. Casas. Madrid: Alianza Editorial, 1977.

ROSSI, P. Francis Bacon: da magia à ciência. Trad. A. F. Bernardini. Londrina: Eduel; Curitiba: Editora UFPR, 2006.

SPEDDING, J.; ELLIS, R. L.; HEATH, D. D. Mr. Bacon in praise of knowledge. In: (Orgs.) The

letters and life of Francis Bacon, vol.I. London: Longman, 1861. Reimp. fac-similar, EUA: Internet Archive, 2007.

"Of the interpretation of Nature." In: (Orgs.). The letters and life of Francis

Bacon, vol. III London: Longman, 1868. Reimp. fac-similar, EUA: Internet Archive, 2007. "Epistola ad Fulgentium." In:

(Orgs.). The letters and life of Francis Bacon, vol. VII. London: Longmans, 1874. Reimp. fac-similar, EUA: Internet Archive, 2007.

THOM, R. Parábolas e catástrofes: entrevista sobre matemática, ciência e filosofia. Lisboa: Publicações Dom Quixote, 1985. 
VICKERS, B. Francis Bacon and the progress of knowledge. Journal of the History of Ideas, 53, 3 , p.495-518, 1992. Disponivel em: <http://www.jstor. org/stable/2709891>. Acesso em 17 de março de 2014.
WHEELER, H. Francis Bacon's 'Verulamium' the common-law template of the modern in english science and culture. Angelaki Journal of the Theoretical Humanities, 4, 1, p.7-26, 1999. Disponível em: <http://www.tandfonline.com/loi/ cang20>. Acesso em 17 de março de 2014. 
